\title{
Harlequin-like syndrome after migrated interscalene catheter bolus injection
}

\author{
Ching-Rong Cheng* and Nav Parkash Sandhu \\ Department of Anesthesiology, University of California San Diego, USA
}

\begin{abstract} injection. presentations.

\section{Introduction}

Interscalene perineural catheters provide prolonged analgesia lasting up to 3 days or longer [1]. Ultrasound guidance has led to increased use of interscalene catheters. These catheters are known to migrate outward or to deeper locations leading to failure and/ or complications from misplaced drug delivery [2]. We are describing a case where catheter migration leads to rare Harlequin syndrome with severe vasospasm of ipsilateral face and scalp and red flushing of contralateral face and scalp.
\end{abstract}

Interscalene catheters have known to migrate leading to failure or even more dangerous complications like intravascular injection related toxicity.

We present a case of ipsilateral facial blanching and contralateral facial flushing (Harlequin-like syndrome) immediately after bolus injection of local anesthetics into interscalene catheter. Reviewing the ultrasound image, the incident was most likely triggered by migrated interscalene catheter with intravascular local anesthesia

This case emphasizes the importance of vigilance in monitoring regional catheters and illustrates value for ultrasonography in investigating unexpected clinical

\section{Case presentation}

A 45 years old healthy male was undergoing an elective right shoulder arthroscopy, labral debridement and repair. His vital signs \& laboratory data were within normal limits. The patient had a right interscalene block using ultrasound guidance and a catheter placement half an hour prior to operation using $2 \mathrm{mg}$ midazolam and $50 \mathrm{mcg}$ of fentanyl for sedation. The patient was given an initial injection of ropivacaine, $0.5 \%$ with epinephrine (1:200000) $30 \mathrm{ml}$ using a $17 \mathrm{G}$ Touhy needle into the interscalene groove under ultrasound guidance. A Flextip catheter ${ }^{R}$ (Arrow International, Reading, PA, USA) was placed in the patient's right brachial plexus and the catheter tip position was then confirmed with an injection of $1 \mathrm{ml}$ air under ultrasound visualization [3]. No immediate complications were observed. The patient had a good sensory and motor block prior to induction of general anesthesia. He then underwent an uncomplicated three and half-hour surgical procedure. In the post anesthesia care unit, Horner syndrome was observed on right side (ipsilateral) and the patient had good pain control. An On-Q pump (Halyard, Irvine, CA, USA) with ropivacaine, $0.2 \%$, set at $8 \mathrm{ml} / \mathrm{hr}$ basal rate, with a $5 \mathrm{ml}$ patientcontrolled bolus every $30 \mathrm{~min}$, was connected to interscalene catheter after a negative aspiration test. After hooking up the pump, patient self-administered a bolus of ropivacaine and immediately experienced nausea. While treating the patient's nausea with dexamethasone $4 \mathrm{mg}$ and prochlorperazine $10 \mathrm{mg}$ intravenously, the PACU nurse noticed that the patient's face had changed color in an interesting pattern (Figure 1). Half of the face on the side of the catheter was pallid and the contralateral side was reddishly flushed with a distinct vertical line of demarcation extending the length of the midline of the face.

There were no signs of contralateral left arm weakness to suggest neuraxial blockade. The catheter was aspirated with no blood return. The local anesthetic infusion was stopped, but the catheter was left in situ. Approximately 15 minutes later patient was reevaluated, and the ipsilateral right face has regained its pink color. An Intravenous dilaudid patient-controlled analgesia with was ordered to treat pain after the block resolved. The next morning the two sides of the face did not differ in color. An ultrasound examination revealed that the catheter tip had migrated out of brachial plexus and was lying adjacent to the transverse cervical branch of thyrocervical artery (Figure 2). Identification of artery was confirmed by color Doppler. The catheter was removed. Following the patient after one year, there was none of this kind of episode happened again.

\section{Discussion}

In our patient, patient had ipsilateral pallor and contralateral reddish flushing of the face with clear demarcation in middle line. His look was like Harlequin syndrome [4].

Harlequin syndrome has been reported in different clinical conditions, including mediastinal neuroma, and medullary infarction. This syndrome was also reported after thoracic epidural anesthesia,

${ }^{*}$ Correspondence to: Ching-Rong Cheng, Department of Anesthesiology, University of California San Diego, USA, E-mail: crcheng@ucsd.edu

Key words: interscalene catheter, regional anesthesia, harlequin syndrome, local anesthetic toxicity

Received: January 29, 2019; Accepted: February 11, 2019; Published: February 14,2019 


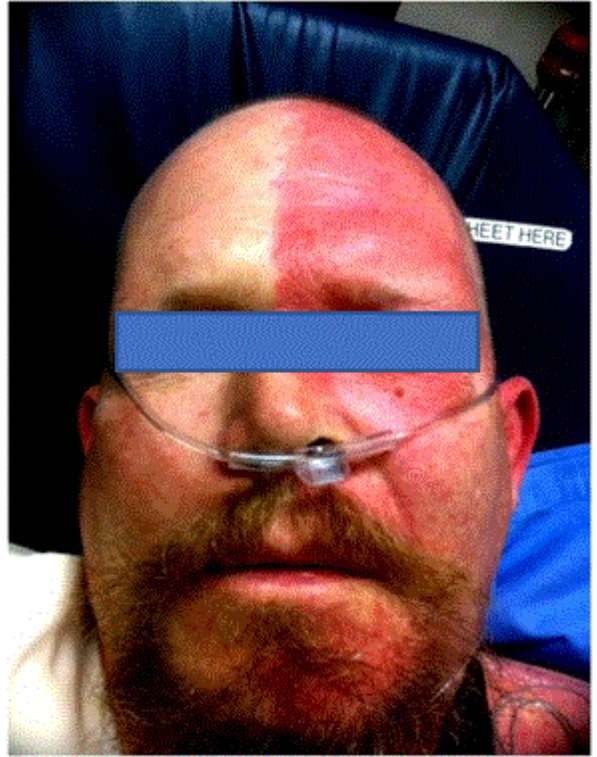

Figure 1. Right facial pallor and left reddish face following bolus into right interscalene catheter

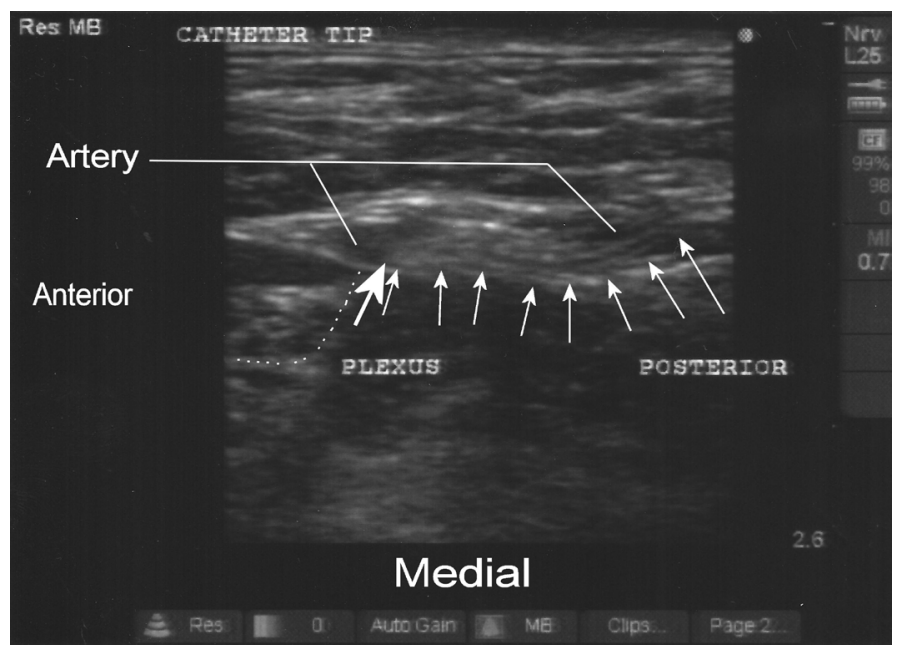

Figure 2. The catheter tip was lying adjacent to the transverse cervical branch of thyrocervical artery

thoracic paravertebral block, intercostal block and interscalene block [5-9]. Although the exact mechanism is not clear yet, most regarded this as a dysfunction of sympathetic innervation on the non-flushing side.

Concerning this patient history and time course, the mechanism to cause this Harlequin-like syndrome first may be due to interscalene block that performed earlier. The preoperative interscalene block blocked sympathetic nerve supply of ipsilateral side (right side), and this sympathetic block was also confirmed in this patient with Horner syndrome in ipsilateral side. The second factor may be there was intravascular local anesthetics injection after bolus dose through interscalene catheter to trigger this syndrome.

The interscalene catheter tip's location in the brachial plexus was confirmed at the time of the block using $1 \mathrm{ml}$ air for an injection test. However, the tip of catheter migrated outwards and was lying adjacent to the transverse cervical branch of thyrocervical artery in the ultrasound scan after the incident. This location leads us to suspect that the On-Q pump bolus delivered after the surgery went into the branch of transverse cervical artery and caused ipsilateral vasoconstriction effects of local anesthetic on the arteries on the right side of the face. Low concentrations of local anesthetic have been shown to cause arteriolar vasoconstriction [10].

Deposition of local anesthetic adjacent to the transverse cervical branch of the thyrocervical artery would be expected to effect small vessels fed by that artery, a localized action rather than one involving half the face. However, if local anesthetic deposition were intraarterial, rapid injection with high pressures could have caused retrograde flow through the very short thyrocervical trunk and subsequently into carotid artery branches. Flow from carotid artery branches could conceivably carry local anesthetic to a large area of the face. Larger distribution of pressurized fluid due to retrograde flow is a plausible explanation. Lowenstein et al calculated that fluid injected into radial artery at wrist at rate of $10-12 \mathrm{ml} / \mathrm{sec}$ can reach innominate artery or aorta [11].

Our explanation based on this mechanism is that block needle traversed through the artery before it reached brachial plexus. Thus, the catheter tip was initially localized in the plexus but with its body passing through the artery. The catheter migrated somewhere in operative period and the catheter tip reached close to artery. Hence, negative aspiration was observed prior to connecting the infusion pump. It is possible during bolus the catheter tip recoiled into transverse cervical artery leading to intra-arterial injection of ropivacaine, followed by further recoil of the catheter tip out of the artery. A retrograde injection reaching the subclavian artery and the common carotid artery led to arterial vasospasm and resultant pallor of the right side of face. Our hypothesis does not have a clear-cut proof, but it is the best explanation for the events that we can conceive.

The contralateral flushing may be a compensatory response to the stress caused by intravascular injection and correction of the vasoconstriction on ipsilateral side. The vasodilation was intact on the contralateral side. So contralateral face showed reddish color. That's why there was such contrast of facial color difference.

There were only two Harlequin-like syndromes related to interscalene block reported in the literature. Hupert reported a similar case of facial vasospasm following interscalene block in 1984 [8]. Hupert C. proposed that local anesthetic had reached the ipsilateral facial nerve near the ear and blocked an active facial vasodilator system mediated by ipsilateral facial nerve. We observed the tip of catheter was far away from facial nerve in our patient, making Hupert's proposed mechanism unlikely.

Adams J. et all also reported another case of Harlequin syndrome following interscalene block [9]. It happened one hour after interscalene block with no Horner syndrome. The author thought inhibition of sympathetic chain of $\mathrm{T} 2$ ganglion may be the cause of this case.

Horner syndrome was observed in our patient, so sympathetic mediated vasoconstriction is ruled out on ipsilateral side. However, this patient showed severe pallor (vasoconstriction) on the ipsilateral side. According to the time course, retrograde arterial injection of ropivacaine into arterial system of the neck was most likely cause this severe vasospasm [12].

Considering the needle trajectory was very superficial in plane of transverse cervical artery in this case. It is a better practice to take a deeper trajectory through belly of middle scalene muscle which would lead to better anchoring of catheter and away from arteries and veins in the intermuscular planes. 
In this case, despite of negative aspiration patient ended up having vasospasm, hence it may be prudent to routinely check the position of catheter tip by sonography before connecting pump, especially in interscalene catheter, because there are many vessels in this area and migration of catheter can cause big problem.

\section{Conclusion}

This is the first reported case where a bolus of ropivacaine through the interscalene catheter cause Harlequin-like syndrome. It also teaches us to be vigilant of migration of interscalene catheter. Routinely check the position of catheter before starting infusion with ultrasound may be helpful to prevent this kind of complication.

\section{References}

1. Borgeat A, Schappi B, Biasca N, Gerber C (1997) Patient-controlled analgesia after major shoulder surgery: Patient-controlled interscalene analgesia versus patientcontrolled analgesia. Anesthesiology 87: 1343-1344. [Crossref]

2. Jenkins CR, Karmakar MK (2005) An unusual complication of interscalene brachial plexus catheterization: delayed catheter migration. Br J of Anaesth 95: 535-537. [Crossref]

3. Sandhu NS, Capan LM (2002) Ultrasound guided infraclavicular brachial plexus block. Brit J Anaesth 89: 254-259.
4. Lance JW, Drummond PD, Gandevia SC, Morris JG (1988) Harlequin syndrome: The sudden onset of unilateral flushing and sweating. J Neurol Neurosurg Psychiatry 51: 635-642. [Crossref]

5. Burlacu CL, Buggy DJ (2007) Intraoperative Harlequin syndrome. Anesth Analg 104 748-749. [Crossref]

6. Nagasaka Y, Wasner G, Sharma B, Fleischmann K (2016) Harlequin syndrome after thoracic paravertebral block. AA Case Rep 6: 48-51.

7. Viswanath O, Wilson J, Hasty F (2016) Harlequin syndrome associated with multilevel intercostal nerve block. Anesthesiology 125: 104-105

8. Hupert C (1984) Contralateral facial blush and ipsilateral facial pallor following interscalene brachial block. Reg Anesth pain Med 9: 203-206.

9. Adams JS, Minzola DJ (2018) Isolated Harlequin syndrome following brachial plexus nerve block via interscalene approach: A case report. AANA 86: 56-58.

10. Johns RA, Seyde WC, DiFazio CA, Longnecker DE (1986) Dose-dependent effects of bupivacaine on rat muscle arterioles. Anesthesiology 65: 186-191. [Crossref]

11. Lowenstein E, Little JW 3rd, Lo HH (1971) Prevention of cerebral embolization from flushing radial-artery cannulas. $N$ Engl J Med 285: 1414-1415. [Crossref]

12. Butt WW, Gow R, Whyte H, Smallhorn J, Koren G (1985) Complications resulting from use of arterial catheters: retrograde flow and rapid elevation in blood pressure. Pediatrics 76: 250-254. [Crossref]

Copyright: (C2019 Cheng C. This is an open-access article distributed under the terms of the Creative Commons Attribution License, which permits unrestricted use, distribution, and reproduction in any medium, provided the original author and source are credited. 